\title{
Chemical Modification of Tryptophan Residues in Abrin-a
}

\author{
Hideki OHba, Nobuyuki Yamasaki* and Gunki Funatsu \\ Laboratory of Biochemistry, Faculty of Agriculture, Kyusyu University, \\ Hakozaki, Higashi-ku, Fukuoka 812, Japan
}

Received December 10, 1990

\begin{abstract}
Chemical modification of tryptophan residues in abrin-a with $N$-bromosuccinimide (NBS) was studied with regard to saccharide-binding. The number of tryptophan residues available for NBS oxidation increased with lowering $\mathrm{pH}$, and 11 out of the 13 tryptophan residues in abrin-a were eventually modified with NBS at $\mathrm{pH} 4.0$, while 6 tryptophan residues were modified at $\mathrm{pH} 6.0$ in the absence of specific saccharides. Modification of tryptophan residues at $\mathrm{pH} 6.0$ greatly decreased the saccharide-binding ability of abrin-a, and only $2 \%$ of the hemagglutinating activity was retained after modification of 3 residues/mol. When the modification was done in the presence of lactose or galactose, 1 out of 3 residues/mol remained unmodified with a retention of a fairly high hemagglutinating activity. However, GalNAc did not show such a protective effect. NBS-oxidation led to a great loss of the fluorescence of abrin-a, and after modification of 3 tryptophan residues/mol, the fluorescence intensity at $345 \mathrm{~nm}$ was only $38 \%$ of that of the unmodified abrin-a. The binding of lactose to abrin-a altered the environment of the tryptophan residue at the saccharide-binding site of abrin-a, leading to a blue shift of the fiuorescence spectrum. The ability to generate such fluorescence spectroscopic changes induced by lactose-binding was retained in the derivative in which 2 tryptophan residues/mol were oxidized in the presence of lactose, but not in the derivative in which 3 tryptophan residues/mol were oxidized in the absence of lactose. Importance of the tryptophan residue(s) in the saccharide-binding of abrin-a is suggested.
\end{abstract}

Lectins from a variety of plants have attracted a great deal of interest because of their unique biological activities such as cytoagglutinating activity, mytogenic activity, and cytotoxicity. ${ }^{1-3)}$ Such biological activities are considered to be initiated by binding of lectins to the carbohydrate receptor on the cell membrane. Abrin-a, a highly toxic lectin from Abrus precatorius seeds, has a molecular weight of 63,000 and consists of two non-identical polypeptide chains (A- and B-chains) linked with a single disulfide bond. ${ }^{4}$ ) This is a lectin specific for galactopyranosides and $N$-acetylgalactosamine and the cytoagglutinating activity is executed by the B-chain. ${ }^{5-7)}$ In this context, the asccharide-binding properties of this lectin have been analyzed by cytoagglutination inhibition tests and physicochemical methods. ${ }^{5)}$ Equilibrium dialysis and spectroscopic studies on the interaction of abrin-a with its specific saccharides have suggested that this lectin has two saccharidebinding sites with different affinities, a high afinity site (HA-site) capable of binding both galactopyranosides and $\mathrm{N}$-acetylgalactosamine, and a low affinity site (LA-site), which can bind galactopyranosides but lacks the afinity for $\mathrm{N}$-acetylgalactosamine, and that there may be a tryptophan residue or residues at the respective binding sites. ${ }^{8)}$ Although the significance of the tryptophan residues in the function of abrin-a has thus been suggested, their specific roles in the saccharide-binding of this lectin have remained unsolved. To attain

* To whom correspondence should be addressed.

Abbreviations: NBS, $N$-bromosuccinimide; GalNAc, $N$-acetyl-D-galactosamine; HA-site, a high affinity binding site; LA-site, a low affinity binding site; UV-, ultraviolet; CD, circular dichroism; 1 or 2-m-abrin-a (+lac), abrin-a which was modified in the presence of lactose and contained 1 or 2 oxidized tryptophan residues/mol; 3-m-abrin-a $(-\mathrm{lac})$, abrin-a which was modified in the absence of lactose and contained 3 oxidized tryptophan residues/mol. 
better understanding of the nature of the saccharide-binding sites of anrin-a, the tryptophan residues in this lectin were modified with $\mathrm{N}$-bromosuccinimide, and the saccharidebinding properties of the modified derivatives were examined. This paper presents direct evidence for the presence of tryptophan at the saccharide-binding sites of abrin-a.

\section{Materials and Methods}

Abrin-a was purified by the method of Lin et al. ${ }^{97}$ from the seeds of Abrus precatorius produced in Thailand, and stored as an ammonium sulfate precipitate at $4^{\circ} \mathrm{C}$. $\mathrm{N}$-Bromosuccinimide, lactose and galactose were obtained from Wako Pure Chemicals Industries Ltd., Osaka. $\mathrm{N}$-Acetylgalactosamine and galactosamine hydrochloride were purchased from Nacalai Tesque Inc., Kyoto. $\mathrm{N}$-Bromosuccinimide was recrystallized from distilled water before use, and all saccharides used belong to the D-series. Other chemicals used were of analytical grade.

Preparation of solutions. The abrin-a solution was prepared by dialyzing the ammonium sulfate precipitate of abrin-a against deionized water at $4^{\circ} \mathrm{C}$. For preparation of the solution of the complex of abrin-a with saccharide, the abrin-a solution was mixed with the saccharide solution before the experiments. All solutions were filtered through a Millipore filter $(0.1 \mu \mathrm{m})$.

Protein concentration. The concentration of abrin-a was measured spectrophotometrically using the extinction coeficient $A_{1 \mathrm{~cm}}^{1 \%}=15.9$ at $280 \mathrm{~nm}$. ${ }^{51}$ The concentration of the modified abrin-a was also measured by the method of Lowry et al. ${ }^{10)}$ using native abrin-a as a standard protein.

NBS-oxidation of abrin-a. The oxidation of tryptophan with NBS was done essentially by the method of Spande et al. ${ }^{11)} \mathrm{A} 2-\mathrm{m} 1$ sample of abrin-a solution $(4.4 \mu \mathrm{M})$ in $0.1 \mathrm{M}$ acetate buffer at a given $\mathrm{pH}$ was placed in a quartz cell and the absorption spectrum was recorded on a Hitachi 200-10 spectrophotometer. The cell compartment was kept at $25^{\circ} \mathrm{C}$ by circulating water from a bath. Under stirring, $10-\mu \mathrm{l}$ of NBS solution at a given concentration was added and after $3 \mathrm{~min}$, the absorption spectrum was measured. To obtain the titration curve for oxidation of tryptophan in abrin-a, 10- $\mu$ 1 amounts of NBS solution $(2.8 \mathrm{~mm})$ were added until the decrease in the absorbance at $280 \mathrm{~nm}$ ceased. The number of tryptophan residues oxidized were calculated by the method of Spande $e t$ al. ${ }^{11}$

Cytoagglutinating activity. Cytoagglutinating activity of abrin-a was measured visually using human O-type blood cells in $5 \mathrm{~mm}$ phosphate-buffered saline $(\mathrm{pH} 7.1)$ at $25^{\circ} \mathrm{C}$ as described in the literature. ${ }^{121}$

Fluorescence spectra of abrin-a and its derivatives. Fluorescence spectra were recorded on a Hitachi 650-10S fluorescence spectrophotometer equipped with a thermostatted cell holder. All measurements were done in $4.4 \mathrm{~mm}$ phosphate buffer $(\mathrm{pH} 7.0)$ containing $90 \mathrm{mM} \mathrm{NaCl}$ at $25^{\circ} \mathrm{C}$. To obtain the association constants for binding of lactose to abrin-a and its derivative, differences in the fluorescence intensity at $320 \mathrm{~nm}$ between the complex of abrin-a (or modified abrin-a) with lactose and free abrin-a (or modified abrin-a) were monitored on the expanding recorder. The change in the fluorescence was assumed to depend on the amount of the complex, and the association constants were obtained according to the following equation:

$$
\frac{\Delta F / F_{345}}{\left[S_{t}\right]}=-K_{\mathrm{a}}^{F} \Delta F / F_{345}+K_{\mathrm{a}}^{F} \Delta F_{\max } / F_{345}
$$

where $\Delta F$ is the difference in the fluorescence intensity at $320 \mathrm{~nm}$ between free abrin-a (or modified abrin-a) and the complex at a given concentration of lactose. $\Delta F_{\max }$ is the maximal fluorescence intensity at $320 \mathrm{~nm}$ where the binding site of abrin-a (or modified abrin-a) was saturated with lactose. $\left[S_{\mathrm{t}}\right]$ and $K_{\mathrm{a}}^{F}$ are the total lactose concentration and the association constant, respectively. $K_{\mathrm{a}}^{F}$ and $\Delta F_{\max }$ were obtained from the Scatchard plot of $\Delta F / F_{345} /\left[S_{t}\right]$ versus $\Delta F / F_{345}$

$C D$ spectra. CD spectra were recorded on a JASCO $\mathrm{J}-600$ spectropolarimeter at $20^{\circ} \mathrm{C}$. The protein concentration was $1.2 \mu \mathrm{m}$ and the light path of the cell was $1 \mathrm{~mm}$. Ellipticity was taken as mean residue ellipticity. In the equation, $[\theta]_{\lambda}=(\theta / 10)(\bar{M} / l c)$ with units of $\mathrm{deg} \mathrm{cm}^{2} / \mathrm{dmol}$, is the observed ellipticity in degrees, $M$ is the mean residue molecular weight, $l$ is the path length in $\mathrm{cm}$, and $c$ is the concentration of protein in $\mathrm{g} / \mathrm{ml}$.

\section{Results}

Susceptibility of tryptophan in abrin-a to NBSoxidation

Figure 1 shows the titration curves for NBS-oxidation of tryptophan in abrin-a at various pHs. It is evident that NBS-oxidation of abrin-a was greatly influenced by $\mathrm{pH}$. The extent of tryptophan oxidation increased with lowering $\mathrm{pH}$, and eleven tryptophan residues/molecule were oxidized at $\mathrm{pH} 4.0$, while only six tryptophan residues/molecule were eventually modified at $\mathrm{pH}$ 6.0. When the modification reaction was done in the presence of $0.2 \mathrm{M}$ lactose at $\mathrm{pH} 6.0$, one tryptophan residue/molecule was protected from the 


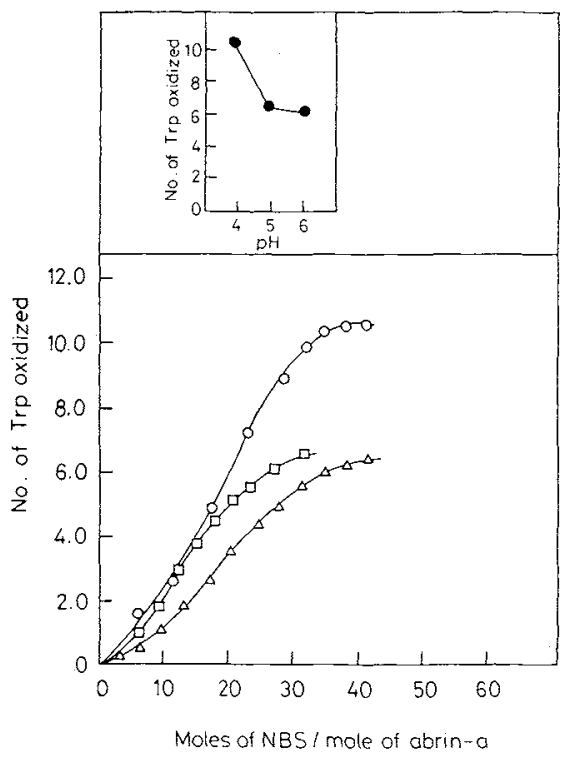

Fig. 1. Effects of $\mathrm{pH}$ on NBS-Oxidation of Tryptophan in Abrin-a.

Two $\mathrm{ml}$ of abrin-a solution $(4.4 \mu \mathrm{M})$ was titrated by successive addition of $10 \mu \mathrm{l}$ of NBS solution $(2.8 \mathrm{~mm})$ at $20^{\circ} \mathrm{C}$. Buffers used for modification reaction were $0.1 \mathrm{M}$ acetate at $\mathrm{pH} 4.0-6.0 .(\bigcirc), \mathrm{pH} 4.0 ;(\square), \mathrm{pH} 5.0 ;(\triangle), \mathrm{pH}$ 6.0 .

modification, as shown in Fig. 2. The same result was obtained when galactose was used in place of lactose (data not shown). In contrast to this, in the presence of $\mathrm{N}$-actylgalactosamine or galactosamine, larger amounts of NBS were required to achieve the same extent of modification, but the number of tryptophan residues eventually oxidized was not changed.

Effects of tryptophan modification on the hemagglutinating activity of abrin-a

The hemagglutinating activity of abrin-a for human O-type blood cells decreased greatly during NBS-oxidation, as shown in Fig. 3. In the absence of specific saccharide, oxidation of one tryptophan residue/molecule led to an approximately $85 \%$ loss of the hemagglutinating activity of abrin-a, and only $2 \%$ of the residual activity was found in the derivative, m-abrin-a (-lac), in which three tryptophan residues/molecule were oxidized. However, another derivative, m-abrin-a (+lac), which was modified in the presence of $0.2 \mathrm{M}$ lactose

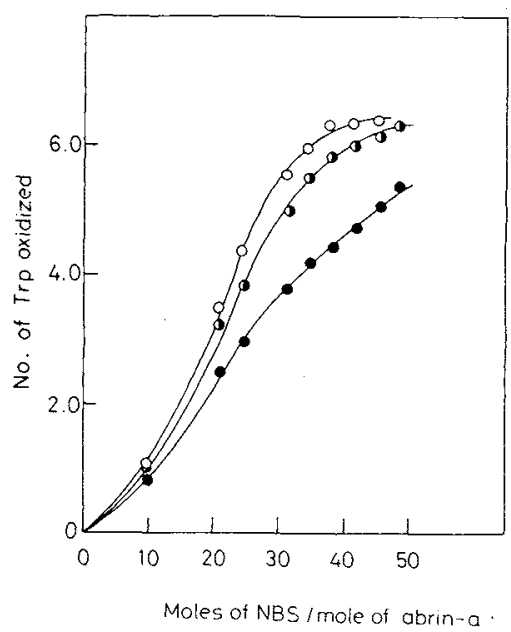

Fig. 2. Effects of Saccharides on NBS-Oxidation of Abrin-a.

The oxidation reactions were done at $\mathrm{pH} 6.0$ and $25^{\circ} \mathrm{C}$ in the absence of saccharide $(O)$ and in the presence of $0.2 \mathrm{M}$ lactose () or $\mathrm{N}$-acetylgalactosamine (()). Other conditions were as described under Materials and Methods.

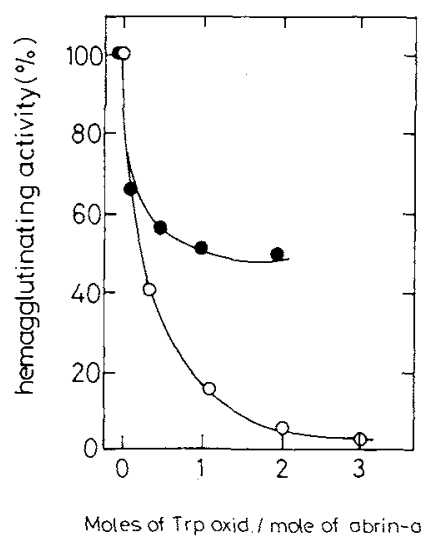

Fig. 3. Effects of NBS-Oxidation on Hemagglutinating Activity of Abrin-a.

The modified abrin-a preparations which were oxidized with NBS at $\mathrm{pH} 6.0$ in the absence $(O)$ and presence $(0$ of $0.2 \mathrm{M}$ lactose were used for assay of hemagglutinating activity. After modification, sample solutions were dialyzed against deionized water, followed by dialysis against $5 \mathrm{~mm}$ phosphate-buffered saline at $\mathrm{pH} 7.0$, and used in the hemagglutinating test.

and contained two oxidized tryptophan residues/molecule retained a fairly high hemagglutinating activity. 
Fluorescence spectra of abrin-a and its derivatives in the presence or absence of lactose

As shown in Fig. 4, the fluorescence spectrum of abrin-a excited at $290 \mathrm{~nm}$ had an emission maximum at $345 \mathrm{~nm}$. NBS-oxidation led to a great loss of the fluorescence of abrin-a, and after modification of three tryptophan residues/molecule, the fluorescence intensity at $345 \mathrm{~nm}$ was only $38 \%$ of that of the unmodified

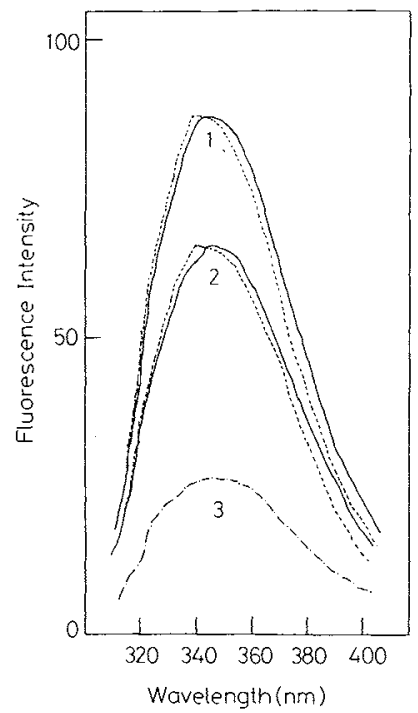

Fig. 4. Fluorescence Spectra of Native- and ModifiedAbrin-a in the Absence and Presence of Lactose.

Solutions of native abrin-a (1), 1-m-abrin-a (+1ac) (2) and $3-\mathrm{m}$-abrin-a (- - ac) (3) were excited at $290 \mathrm{~nm}$. The spectra were obtained in the absence $(-)$ and presence $(\ldots \ldots)$ of $10 \mathrm{~mm}$ lactose. The protein concentration was $0.75 \mu \mathrm{M}$. Abrin-a was modified with NBS at $\mathrm{pH} 6.0$ and dialyzed against phosphate buffer at $\mathrm{pH} 6.9$. abrin-a. Furthermore, the fluorescence spectrum of abrin-a shifted to shorter wavelength by $5 \mathrm{~nm}$ upon the addition of lactose. Such a lactose-induced blue shift of the fluorescence spectrum was also observed for the active derivative, m-abrin-a $(+\mathrm{lac})$ but not for the inactive derivative, m-abrin-a ( - lac). By analyzing the variation of the fluorescence intensity at $320 \mathrm{~nm}$ with increasing lactose concentration, the association constants for binding of lactose to abrin-a and its active derivative were calculated using equation 1 . The Scatchard plots for binding of lactose to

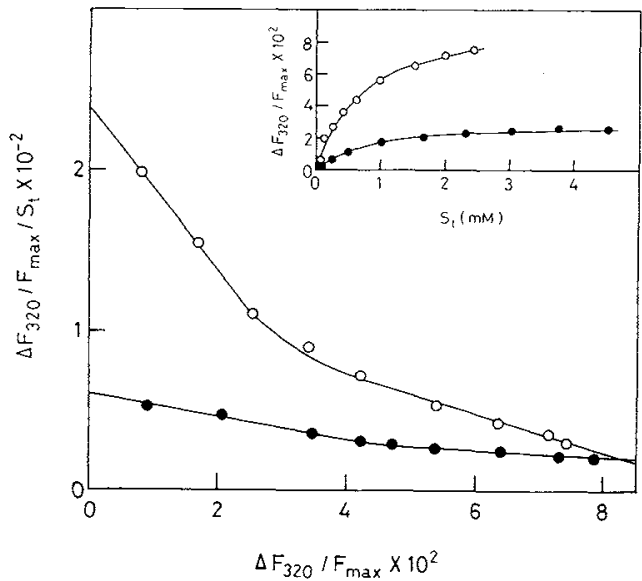

Fig. 5. Scatchard Plots for Binding of Lactose to Native- and NBS Oxidized-Abrin-a Obtained from Fluorescence Spectroscopic Data.

Spectral measurements were done under the conditions as described in Materials and Methods. The plots of native abrin-a $(O)$ and 2-m-abrin-a (+lac) (O) were obtained. The plots of $\Delta F_{320} / F_{345}$ versus $S_{\mathrm{t}}$ are in the inset.

Table I. EfFects of NBS-Oxidation ON the Hemagglutinating Activity AND AFFinity to LACtose of AbRin-a.

Abrin-a was modified with NBS at pH 6.0 and $25^{\circ} \mathrm{C}$. Details are described in Materials and Methods.

\begin{tabular}{cccc}
\hline Proteins & No. of Trp oxidized & $\begin{array}{c}\text { Hemagglutinating activity } \\
(\%)\end{array}$ & $\begin{array}{c}\text { Association constant for } \\
\text { binding of lactose } K_{\mathrm{a}}^{F} \\
\left(\mathrm{M}^{-1}\right)\end{array}$ \\
\hline $\begin{array}{l}\text { Modified in } \\
0.2 \mathrm{M} \mathrm{Lac} \\
\text { without saccharide }\end{array}$ & 2.0 & 50 & $\begin{array}{c}0.5 \times 10^{3} \\
0.3 \times 10^{3} \\
\text { n.d. }\end{array}$ \\
Unmodified & 3.0 & 5 & $5.4 \times 10^{3}$ \\
\end{tabular}




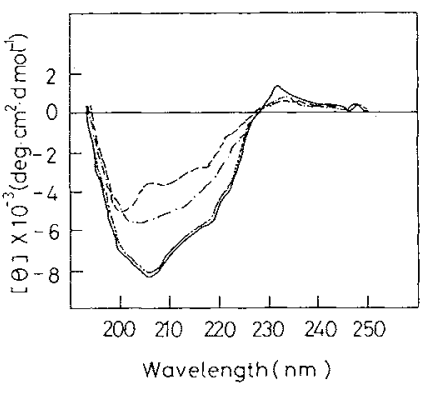

Fig. 6. Circular Dichroism Spectra of Abrin-a as Influenced by $\mathrm{pH}$.

Spectra were measured at pH $7.0(-), \mathrm{pH} 6.0(\cdots \cdots)$, pH $5.0(-\cdot-\cdot)$ and $\mathrm{pH} 4.0$ (----) . The following buffers of 0.1 ionic strength were used throughout the experiment; phosphate, $\mathrm{pH} 7.0$ and $\mathrm{pH} 6.0$; acetate, $\mathrm{pH} 5.0$ and $\mathrm{pH}$ 4.0. The measurements were done at $20^{\circ} \mathrm{C}$.

abrin-a and m-abrin-a (+lac) both had biphasic curvatures, as shown in Fig. 5. From the biphasic Scatchard plots, two association constants $\left(K_{\mathrm{a} 1}\right.$ and $\left.K_{\mathrm{a} 2}\right)$ were obtained (Table I). The larger one $\left(K_{\mathrm{a} 1}\right)$ given for m-abrin-a $(+$ lac) was less than $10 \%$ that given for abrin-a, while the smaller one $\left(K_{\mathrm{a} 2}\right)$ given for the former was about $23 \%$ that given for the latter.

\section{Effects of $p H$ on the $C D$ spectrum of abrin-a}

The CD spectrum of abrin-a varied with $\mathrm{pH}$, as shown in Fig. 6. The spectrum measured at pH 7.0 had negative CD bands at 207, 218, and $220 \mathrm{~nm}$ and a positive band at $230 \mathrm{~nm}$. An almost identical spectrum was obtained at $\mathrm{pH}$ 6.0. However, the $\mathrm{CD}$ spectrum changed drastically below $\mathrm{pH} 5.0$, and the molar ellipticities at the above wavelengths decreased greatly. These results indicate that the main chain configuration of abrin-a was altered in the acidic region.

\section{Discussion}

The results presented here provide some insight into the states and roles of tryptophan residues in abrin-a. Abrin-a contains 13 tryptophan residues per molecule. As demonstrated here, 3 out of 13 tryptophan residues in abrin-a were highly susceptible to NBS at
$\mathrm{pH}$ 6.0. This suggests that these 3 tryptophan residues are located on or near the surface of the abrin-a molecule at neutral $\mathrm{pH}$. Such a view is consistent with the fluorescence spectroscopic data. The emission maximum at $345 \mathrm{~nm}$ as found in the fluorescence spectrum of abrin-a excited at $290 \mathrm{~nm}$ is characteristic of tryptophan and solely due to the exposed tryptophan. ${ }^{13,14)}$ Oxidation of 3 tryptophan residues/molecule led to a $70 \%$ loss of the fluorescence of abrin-a, indicating that these 3 tryptophan residues are dominant chromophores contributing to the fluorescence of abrin-a. It is evident that the extent of tryptophan modification with NBS is greatly influenced by $\mathrm{pH}$. Below pH 5.0, the number of tryptophan residues eventually oxidized with NBS increased with lowering of $\mathrm{pH}$, and 11 tryptophan residues/molecule were oxidized at $\mathrm{pH}$ 4.0. CD data clearly indicate that a gross conformational change of abrin-a is induced below pH 5.0. Taking these facts into account, it is reasonable to consider that the increase in the extent of tryptophan oxidation in abrin-a as observed below $\mathrm{pH} 5.0$ is principally due to the exposure of the buried tryptophan residues on the surface of the protein molecule by conformational change.

It is noteworthy that modification of one tryptophan residue/mole led to a $85 \%$ loss of the hemagglutinating activity of abrin-a, but in the presence of lactose one tryptophan residue/mole escaped from the modification reaction and a fairly high hemagglutinating activity was retained. There is a possibility that NBS attacks tryosine in addition to tryptophan. In this case, however, such a possibility is negligible since an isosbestic point was found at $269 \mathrm{~nm}$ in the UV-absorption spectrum of abrin-a during NBS-oxidation (Fig. 7). If tyrosine is oxidized, such an isosbestic point should not be observed. ${ }^{15)}$ These results suggest that one of the three tryptophan residues susceptible to NBS-oxidation at $\mathrm{pH} 6.0$ is closely associated with the saccharide-binding of abrin-a. From the spectroscopic studies on the interaction of abrin-a with its specific saccharides, we previously suggested that the 


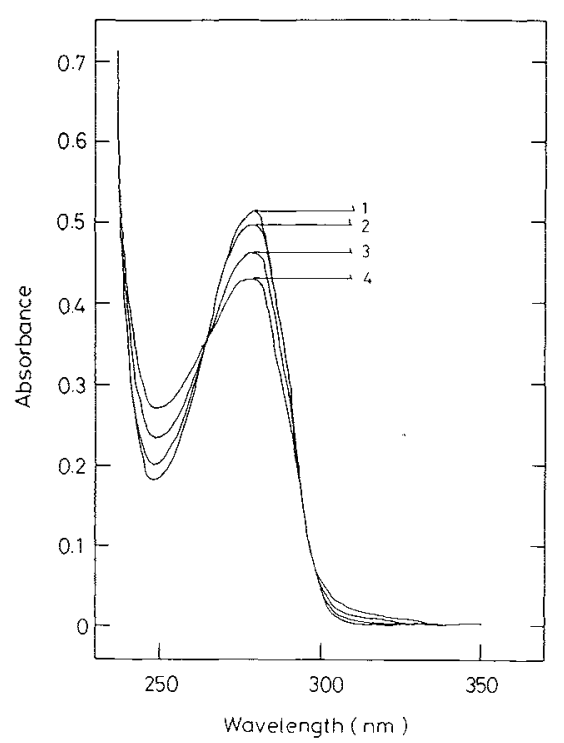

Fig. 7. Change in the Absorption Spectrum of Abrin-a during the NBS-Oxidation.

Two $\mathrm{ml}$ of abrin-a solution $(4.4 \mu \mathrm{M})$ was reacted with $10 \mu \mathrm{l}$ of NBS solution at a given concentration at $\mathrm{pH} 6.0$. (1), $0 \mathrm{M} ;(2), 44 \mu \mathrm{M} ;(3), 66 \mu \mathrm{M} ;(4), 88 \mu \mathrm{M}$.

binding of specific saccharides to abrin-a altered the environment of the tryptophan residue(s) at or near the saccharide-binding site of abrin-a. ${ }^{8)}$ It is plausible that the lactoseinduced change in the environment of the tryptophan at the saccharide-binding site of abrin-a decreased the susceptibility of the tryptophan to NBS-oxidation, and thereby the saccharide-binding ability was retained as observed for the active derivative, $\mathrm{m}$-abrin-a (+lac), which was modified with NBS in the presence of lactose.

In a previous work, we demonstrated that the B-chain of abrin-a has two saccharidebinding sites with different affinities, a high affinity binding site (HA-site) and a low afinity binding site (LA-site), and the binding of saccharides to the respective sites can be monitored by fluorescence spectroscopy. ${ }^{8)}$ To attain better understanding of the nature of the modified abrin-a, the binding of lactose to the NBS-oxidized derivatives of abrin-a was analyzed by fiuorescence spectroscopy. It is evident that the fluorescence spectrum of the active derivative, m-abrin-a ( + lac) shifted to a shorter wavelength upon binding with lactose similarly to that of native abrin-a, but such a shift of the spectrum was not observed for the inactive derivative, m-abrin-a $(-1 \mathrm{ac})$. By analyzing the fluorescence spectroscopic data, two association constants $\left(K_{\mathrm{a} 1}\right.$ and $\left.K_{\mathrm{a} 2}\right)$ were obtained for the binding of lactose to $\mathrm{m}$-abrin-a $(+\mathrm{lac})$, but their values were smaller than those obtained for the binding of this saccharide to abrin-a. Since $K_{\mathrm{a} 1}$ and $K_{\mathrm{a} 2}$ are representative of the affinities of saccharides for the HA-site and the LA-site, respectively, ${ }^{8)}$ it is reasonable to consider that the $\mathrm{HA}^{-}$and $\mathrm{LA}$-sites in m-abrin-a $(+\mathrm{lac})$ can interact with saccharide with low afinities. Low affinities of the binding sites of m-abrin-a $(+\mathrm{lac})$ may be ascribed to the modification of the tryptophan residues other than the tryptophan residue involved in the saccharide-binding, and this may produce a $50 \%$ loss of the hemagglutinating activity of abrin-a during NBS-oxidation even in the presence of lactose.

Evidence for the presence of tryptophan at the saccharide-binding site has been obtained for several lectins. ${ }^{16-21)}$ It has been reported that modification of tryptophan decreases the saccharide-binding abilities of ricin $\mathrm{D}$, a toxic lectin like abrin-a, found in castor beans (Richinus communis) ${ }^{16)}$ castor bean hemagglutinin, ${ }^{17)}$ and Abrus precatorius agglutinin, which is relatively non-toxic but a hemagglutinating lectin with a molecular weight of $130,000 .{ }^{18)}$ As demonstrated here, the hemagglutinating activity of abrin-a was abrogated by modification of three tryptophan residues/mole in the absence of lactose. Considering that abrin-a is a divalent lectin and the hemagglutination is executed by two binding sites on the B-chain, we conclude that in each binding site there is a tryptophan residue which is important for saccharidebinding. Studies are being done to elucidate the location and the specific roles of these tryptophan residues.

\section{References}

I) I. J. Goldstein and C. E. Hayes, Adv. Carbohydr. 
Chem. Biochem., 35, 127 (1978).

2) H. Lis and N. Sharon, Ann. Rev. Biochem., 42, 54 (1973).

3) A. Novogrodosky and E. Kachalski, Biochim. Biophys. Acta, 228, 579 (1971).

4) S. Olsnes, "Methods in Enzymology," Vol. 50, ed by V. Ginsburg Academic Press Inc., New York, 1978 , p. 323.

5) S. Olsnes, E. Saltvedt and A. Pihl, J. Biol. Chem., 249, 803 (1974).

6) C. H. Wei, C. K. Koh, P. P. Pfudere and J. R. Einstein, J. Biol. Chem., 250, 4790 (1975).

7) S. Olsnes and A. Pihl, "Molecular Action of Toxins and Viruses," ed. by P. Cohen and S. van Heynigen, Elsevier Biomedical Press, New York, 1982, p. 51.

8) H. Ohba, N. Yamasaki and G. Funatsu, Agric. Biol. Chem., 54, 1995 (1990).

9) J. Y. Lin, T. C. Lee, S. T. Hu and T. C. Tung, Toxicon, 19, 41 (1981).

10) O. H. Lowry, N. J. Rosebrough, A. L. Farr and R. J. Randall, J. Biol. Chem., 193, 265 (1951).

11) T. F. Spande, N. M. Green and B. Witkop,
Biochemistry, 5, 1926 (1966).

12) N. Absar and G. Funatsu, J. Fac. Agr. Kyushu. Univ., 29, 103 (1984).

13) R. C. Kelley and P. H. Von Hippel, J. Biol. Chem., 252, 7299 (1976).

14) M.S. Herrman and D. W. Behnke, Biochim. Biophys. Acta, 667, 397 (1981).

15) S. R. Patanjali, M. J. Swany, V. Anatharam, M. I. Islam and A. Surolia, Biochem. J., 217, 773 (1984).

16) T. Hatakeyama, N. Yamasaki and G. Funatsu, $J$. Biochem., 99, 1049 (1986).

17) N. Yamasaki, N. Absar and G. Funatsu, Agric. Biol. Chem., 49, 3301 (1985).

18) N. Yamasaki, N. Absar and G. Funatsu, Agric. Biol. Chem., 52, 569 (1988).

19) G. S. Hassing and I. J. Goldstein, Biochim. Biophys. Acta, 271, 388 (1972).

20) M. Cermakova, G. Entlicher and J. Koureck, Biochim. Biophys. Acta, 420, 236 (1976).

21) J-P. Privat, R. Lotan, P. Bouchard, N. Sharon and M. Monsigny, Eur. J. Biochem., 68, 563 (1976). 